\title{
CAMilo E AS CoISAS ESPANTOSAS
}

\section{Camilo and the amazing things}

\author{
Patrícia da Silva Cardoso*
}

\begin{abstract}
RESUMO
O crime, a infâmia, o insólito - de origem sobrenatural ou não - são os elementos de base na constituição do modelo literário gótico, do qual Camilo Castelo Branco não andou longe. A esse propósito, Jacinto do Prado Coelho observa que, se depois do Livro Negro o romancista tendeu a dedicar-se à observação da realidade portuguesa, "simplificou os enredos, [...] até ao fim da sua carreira [...] há-de ceder, de vez em quando, [...] à narração de aventuras terrificantes, roubos, assassínios, perseguições e encontros surpreendentes [...]". Trata-se, nesta observação, de distinguir uma prática literária que correspondesse a uma "concepção mais elevada da sua "arte" daquela voltada para a satisfação do público em seu gosto pelo folhetinesco. Neste artigo interessará discutir em que medida a incorporação daqueles elementos góticos pelo romancista ultrapassa tal compromisso com o folhetinesco - associado à fruição descompromissada - para ser um importante instrumento na reflexão acerca do lugar do literário na sociedade moderna, a que Camilo se dedicou ao longo de sua carreira.
\end{abstract}

Palavras-chave: Camilo Castelo Branco; romance gótico; modernidade.

\footnotetext{
ABSTRACT

Crime, infamy and the unusual - supernatural by origin or not - are the elements constituting the base of the gothic literary model, from which Camilo Castelo Branco has not kept himself very far. In this regard, Jacinto do Prado Coelho observes that, even if after Livro Negro the novelist tended to dedicate him- 
self to observing the Portuguese reality, "simplified the plots, $[\ldots]$ up to the his career's end [...] giving way, every once in a while, $[\ldots]$ to narrating terrifying adventures, thefts, murders, chases and surprising encounters [...]" This remark is about the distinction between a literary practice that corresponds to a "higher conception of his "art" and the one that is directed to satisfying the public's feuilleton-like tastes. This article will discuss up to what point the novelist's embodiment of those gothic elements goes beyond the commitment with the feuilleton style - associated with the uncommitted enjoyment - to become an important tool to consider the space given to literature in modern society, to which Camilo dedicated himself throughout his career.

Keywords: Camilo Castelo Branco; gothic novel; modern world.

Num artigo de caráter memorialístico-encomiástico, Camilo Castelo Branco evoca seu tempo de juventude em Vila Real, quando, juntamente com Guilhermino de Barros, dedicava-se, ele assim o registra, a tracejar de negro suas inspirações caudalosas em resmas de papel ordinário. A orientar tanto a memória quanto o encômio, está a distinção dos interesses, ou das inspirações, dos dois companheiros: enquanto Guilhermino voltava-se para a Idade Média, Camilo “já fisgava osgas nos escombros contemporâneos”. No intuito de marcar o vínculo do amigo com seu tema de eleição, o autor continua, dizendo que ele "não abria mão do romance nem dos enredos baseados nas sentimentalidades arqueológicas. Impulsionava-o a sua velha afeição a Walter Scott; não o enliçavam tramoias engenhosas de Sue e Dumas; a vida moderna, a baldear a sua lama dos palácios para as tabernas e dos salóes para os alcouces, não o deleitava" ${ }^{1}$.

A partir deste olhar lançado ao passado cria-se um duplo movimento, a envolver as imagens de permanência e mudança. Se no momento da escrita é a saudade o que marca o discurso - a juventude vai longe, os amigos seguiram cada um seu caminho, enfim, o tempo é outro - a identificação e caracterização daqueles gostos juvenis servem para indicar o quanto do passado perdura no presente, uma vez que a carreira literária de ambos acabou por desenvolver-se a partir daqueles impulsos. Se considerarmos esse um período de formação, torna-se bastante significativo que Camilo, mesmo indiretamente, por contraste, já que o objeto de sua atenção é Guilhermino de Barros, associe sua prática como o ficcionista profissional em que se transformou ao mundo do romance popular, folhetinesco (afinal, os nomes de Sue e Dumas são referidos a propósito de suas “tramoias engenhosas”), ao configurá-lo como sua base formativa e, mais que isso, seu traço distin-

1 BRANCO, Camilo Castelo. Esboços e perfis literários. Boémia do espírito. Porto: Lello \& Irmão, 1959, p. 234-235. 
tivo. Assim é que o momento da lembrança extrapola os limites da evocação saudosista para indicar aquilo que o presente conserva do passado.

Aceitando-se que a imagem da produção camiliana criada pelo texto é de continuidade, pode-se concordar, ao menos em parte, com Jacinto do Prado Coelho quando afirma que, se por um lado, depois do Livro Negro, Camilo tendeu a dedicar-se à observação da realidade portuguesa

[...] simplificou os enredos, tornou mais naturais situações e personagens, substituiu os homens fatais decalcados em Arlincourt e em Sue por tipos castiços da nossa terra [...]. [Por outro lado,] até ao fim da sua carreira [...] há-de ceder, de vez em quando, ao folhetinesco, à narração de aventuras terrificantes, roubos, assassínios, perseguições e encontros surpreendentes $[\ldots]^{2}$.

Ocorre que, dado o peso assumido pelo universo folhetinesco no texto memorialístico, aquilo que o crítico identifica como desvios transforma-se na identidade do romancista, daí sua persistência ao longo de sua carreira. Concluí-lo está absolutamente longe de implicar numa simplificação da produção camiliana, pois não se trata de defender que esta se exerça nos termos impostos por um modelo específico ou, ainda, de se assumir que a simples presença de elementos folhetinescos comprometa o realismo dessa produção - distinção em si problemática pois implica na dependência da seriedade da narrativa a um padrão realista. Interessa-me justamente o oposto disso, ou seja, aceitando seu reconhecimento do modelo folhetinesco como uma importante referência, acompanhar o modo como Camilo se apropria de certos aspectos desse modelo para construir uma diç̧ão própria, forte a ponto de não permitir que se ponha em sossego quem se esforçar por descrever sua trajetória numa perspectiva teleológica, "superando" um romantismo de possibilidades restritivas para alcançar um realismo mais abrangente e profundo em sua seriedade. Trata-se de um esforço de leitura que, a partir da obra de Camilo, pode ajudar a redimensionar as relações entre o mundo do "terror grosso" e a circunspecção realista.

Volto ao trecho de Prado Coelho há pouco citado para usá-lo como ponto de partida, aproveitando os três títulos que ele dá como exemplos daquelas recaídas do autor no folhetinesco, Coisas espantosas (1862), $O$ esqueleto (1865) e $O$ demónio do ouro (1873-1874). Em cada um deles é possível identificar certos elementos que, sem maiores dificuldades, os vinculam àquele universo do "terror grosso", sinteticamente descrito por Prado Coelho 
como um conjunto de "novelas complicadas, horripilantes e impossíveis, eivadas não raro de humanitarismo e de socialismo românticos" . Preocupado em acompanhar aquela transição para o realismo, mais à frente, a propósito de Os mistérios de Lisboa e o livro negro do padre Dinis, o crítico observa a presença da "notação direta e incisiva do real, embora se subordine à intenção de produzir um efeito espetacular no leitor" de aspectos que "não fazem porém esquecer que as duas novelas são, em conjunto, puro folhetim para aterrar e enternecer o leitor burguês" ${ }^{5}$. Forma-se deste modo uma associação direta entre os componentes do modelo e a superficialidade do conteúdo, reforçada pelo fato de as eventuais incursões no realismo não serem a sério, mas sim instrumentos a serviço da distração do leitor burguês.

É importante dizer que a leitura de Prado Coelho está em perfeita sintonia com a compreensão dominante na crítica a respeito desse tipo de literatura, habitualmente abrigada sob o rótulo "de entretenimento". É o que se encontra, por exemplo, em "O século sério", de Franco Moretti, que se vem destacando no campo da crítica literária com sua proposta de mapeamento da literatura mundial. Nesse texto, ele apresenta uma descrição da seriedade como elemento norteador da narrativa de ficção do século XIX, associando-a ao gosto burguês. Há aqui um contraste com o que acima lemos de Jacinto do Prado Coelho, que não chega a comprometer os pontos de contato entre ambos, já que na base de argumentação de Moretti está a distinção entre entretenimento, que seria o grande objetivo da literatura de massa, e a referida seriedade, compreendida como "a impessoalidade, a imprecisão, a conduta de vida regular e metódica, certo distanciamento emotivo" ", características que não é difícil associar à vertente realista. Veja-se que à mudança de responsabilidade pela falta de seriedade não corresponde uma outra, na relação de oposição entre o entretenimento e tal seriedade.

Esse estado de coisas leva-nos a considerar a hipótese de que o realismo, que permanece como o objetivo final - semelhante muitas vezes a um messias que se anuncia e espera ansiosamente mas nunca se consegue ter a certeza de que tenha encarnado - aparece como um bem tão precioso e frágil que qualquer deslize nos afasta dele, irremediavelmente, daí essa preocupação em manter o terreno sempre limpo, sem traços de irracionalismo (aí entram os temas horripilantes, as ações complicadas, as situações impossíveis). A disciplina crítica, preocupada talvez em delimitar o campo de ação da literatura de massa, outro nome para a de entretenimento, elege

3 Op. cit., p. 287.

4 Ibidem, p. 301.

5 Ibidem, p. 302.

6 MORETTI, Franco. O século sério. In: A cultura do romance. São Paulo: CosacNaify, 2009. p. 824. 
o grau de realismo (e sua complexidade) como uma baliza, na tentativa de recuperar uma distinção perdida justamente no momento em que o romance tomou a cena, ganhando popularidade e comprometendo a fundo a distinção entre o elevado e o baixo que durante séculos regulou a qualidade do produto literário.

Disso decorre pelo menos um problema, já que, na base da "novela do terror grosso", encontra-se um elemento fundamental para a experiência moderna, qual seja, a dupla constituição do indivíduo - social e subjetiva. Unida à percepção da complexidade em que se desdobrava a noção de indivíduo estava a própria noção de racionalidade: quando se começa a considerar que "o não-divisível" explica mal ou apenas parcialmente o termo indivíduo, quando este indivíduo começa a perceber-se vários, abre-se um abismo no fundo do qual estão forças de natureza misteriosa, como a loucura e o sobrenatural. Nesse cenário, à volta da segunda metade do século XVIII, o "terror grosso" foi um espaço, na perspectiva do imaginário, em que se projetou a complexidade dessas novas forças entrelaçadas àquelas que se abandonavam, que se queria considerar ultrapassadas, num ambiente em que a confiança num tipo de racionalidade que anulava qualquer mistério tornava-se hegemônica. Como se vê, na origem, nada o associa ao entretenimento descompromissado, pelo contrário, a atenção que atrai dá a medida de sua importância na figuração de uma nova forma de sensibilidade. E será justamente a recepção altamente positiva que rapidamente o transformará no estereótipo da superficialidade.

Nas primeiras experiências do que depois consolidou-se como modelo - refiro-me a $O$ castelo de Otranto, de Horace Walpole, o interesse por aquela dupla constituição do indivíduo traduziu-se pela incorporação da melancolia como um estado de ânimo importante para marcar o voltar-se dos personagens para sua subjetividade, um plano interior da existência, nem sempre partilhável no ambiente social e, mais complexo que isso, nem sempre passível de ser transformado em discurso. Em $O$ castelo de Otranto a ação frenética faz-se acompanhar de elementos que deem conta do jogo tenso entre vida social e vida subjetiva. Não é à toa, então, que o desfecho da narrativa seja marcado não apenas pela resolução, para o bem, de todos os problemas, mas também pela manutenção da melancolia que envolve $o$ Theodor, o herói que, como diz o narrador, precisará de tempo para superá-la. Só então, depois do fim do romance, ele terá, quem sabe, seu final feliz. Longe, portanto, do alcance do leitor - uma abertura excessiva, uma falta de garantia que representa uma considerável perturbação da ordem narrativa.

Já no momento de consolidação do modelo que foi beneficiário da estrutura criada por narrativas como essa, será preciso garantir que, ao final, o leitor sinta-se pacificado, absolutamente satisfeito com a narrativa 
e, graças a ela, consigo próprio e com seu lugar social. Contrastando com a atmosfera de $O$ castelo de Otranto, em que o feérico se contamina com o melancólico (um estado psicológico em que o abismo é experimentado pela sensação de falta sem objeto), Os mistérios de Paris, de Eugène Sue promoverão o feérico visando a saciedade. Finda a narrativa, depois das centenas de peripécias em que esteve envolvido um sem-número de personagens, o que se observa, como diz Umberto Eco, é que

ninguém "muda" [...]. Quem se converte já era bom no começo, quem era mau, morre impenitente. Nada acontece que pode preocupar ninguém. O leitor é consolado, seja porque centenas de coisas admiráveis acontecem, seja porque estas coisas não alteram o movimento da maré da realidade. [...] O livro faz disparar uma série de mecanismos gratificadores, entre os quais o mais completo e consolador é o fato de que tudo mantém-se em ordem. E aquilo que muda, muda na dimensão do fantástico puro ${ }^{7}$.

Comparando-se o que se lê em $O$ castelo de Otranto com o que se encontra em Os mistérios de Paris pode-se dizer que, numa altura em que o funcionamento do modelo depende da pacificação, que está ausente do texto matricial, Camilo Castelo Branco recupera o que foi deixado para trás - a perturbação efetiva, não epidérmica - e o reinsere no modelo, de maneira a problematizar seu alcance e, ao mesmo tempo, levar adiante a discussão sobre a individualidade que o texto de Walpole promovia. Nas três obras referidas por Prado Coelho Camilo trabalhará a tensão entre os clichés do modelo e as densas questões que o enformaram e tenderam a ser obscurecidas em seu processo de consolidação, de maneira a restaurar seu uso como agente de reflexão, além de instrumento de fruição. Assim é que, em Coisas espantosas, não apenas há mudanças, como estas afrontam as convenções, sejam elas definidas no âmbito ficcional, sejam no plano da realidade.

A maior evidência da presença dessa tensão incorporada por Camilo encontra-se na distância que separa os títulos, altamente promissores de horror (de variadíssima ordem) e mistério daquilo que efetivamente compõe as tramas. Nesse sentido o primeiro deles é exemplar. As Coisas espantosas são na verdade um conjunto de pessoas e situações que escapam às convenções. Seu mistério não reside em seu caráter sobrenatural, mas em sua existência no plano real, a despeito do que as regras sociais e ideológicas determinam. Começando no nível anedótico ("Eu pinto, pela primeira Milano: BUR-Rizzoli, 2011. p. 26-27. Tradução nossa. 
vez na minha vida, galegos credores da imortalidade"), que o é apenas na superfície, apresentam-se ao leitor Gregório, o galego trabalhador, que enriquece honestamente e cuja imagem de probidade será valorizada pelo narrador ao longo do texto, e a justa elevação de sua mulher, Rosa, como ele senhora de baixa extração econômica e social, à condição de Dona. Estas "coisas espantosas" estão a serviço da radical separação de um par poderoso quando se fala em convenção: origem social e caráter. Gregório é usado pelo autor na defesa da completa independência entre elas e, ao mesmo tempo, para manter dentro dos limites do humano o bom caráter do personagem, revestindo-o das contradições que lhe são naturais. A humanidade deste bom caráter é-nos apresentada no início da narrativa, através das "quedas" de Gregório na lábia de Carlota e Joana. Na terceira delas, dirá o narrador:

Esta terceira queda de Gregório é menos desculpável que as outras: atendendo porém a que o coração humano, despojado das galas do amor, se veste de preto, repele o doce alimento das sensações generosas, e ama nutrir-se de vícios e indignidades, tem desculpa o coração de Gregório como o de tantos Manfredos, que o leitor festeja e imita, porque não nasceram em Santiago de Compostela. Sempre injustos e inconsequentes, olhamos com certa seriedade e acatamento para o homem bem nascido e educado, que sofreu revezes na luta do coração com a sociedade, ou tragou o fel da perfídia, e protestou depois vingar-se da espécie humana, seja imolando no altar da sua vindita inocentes virgens, seja afrontando perigos da guerra e barateando a vida contra a morte que lh'a respeita, e devolve cheia de invejáveis triunfos ${ }^{9}$.

O trecho ilustra bem o que venho apontando sobre o modo como Camilo lida com seus modelos. Nele, é defendido o respeito pelo indivíduo, que pode ser bom e fazer asneiras ou mau e ter grandes gestos, independentemente de sua origem ou posição social, a partir da comparação com Manfredo, o protagonista de $O$ castelo de Otranto. Responsável por todo o horror e pela série de tragédias que ocorrem na narrativa, esse personagem da nobreza arrepende-se, resgatando com isso uma dignidade que nunca teve, já que, quando o leitor é apresentado a ele, sua maldade está sendo exercitada a todo vapor. Como bônus, a comparação do narrador dá a medida da diferença de recepção entre um texto produzido no âmbito de uma literatura considerada central, além-Pirineus, e outro, Galícia abaixo. 
Segue espantando o amor entre Augusto e Carlota, legitimadíssimo pelo narrador, apesar de reprovado pelas convenções da lógica e da moral - a moça fora sua ama e amante de seu pai, tramando, com Manuel de Castro, seu outro amante, o desvio da herança de Augusto. Coroando esse cenário de espanto, num contexto em que, como veremos, a individualidade, que dava seus primeiros passos em $O$ castelo amadurece a olhos vistos, prova maior daquele bom caráter de que Gregório é exemplo, estão a capacidade de perdoar, que é dominante entre os personagens - com as devidas exceções porque, afinal, a polarização entre bem e mal não faz o menor sucesso nesta narrativa - e a amizade que os une, permitindo a interlocução, o encontro com o outro. Mesmo que dele saia a decisão de que o melhor seja a despedida, como acontece justamente com Augusto e Carlota. Muito diverso será $\mathrm{o}$ ambiente de $O$ esqueleto.

Neste romance, a apropriação crítica do modelo continua a ser perceptível no contraste entre a promessa do título e o efetivo conteúdo da narrativa, já que o grosso da ação discute as relações humanas a partir da troca de casais - a serviço da qual está a estrutura da peripécia - e não ao arrepio divertido e sem consequências provocado pelo amontoado de ossos do título. Arrepiante a valer é a imagem criada pelo romance de um mundo em que aquele individualismo tenuemente - na perspectiva do nosso tempo - representado por Walpole finalmente triunfou, carregando esse triunfo desdobramentos nem sempre bem-vindos. Nesse mundo não há mais qualquer hipótese de encontro, de interlocução entre indivíduos, como vemos acontecer em Coisas espantosas. Pensando no que o modelo determina, como depois se dirá em Hollywood, nada mais é sagrado, a começar pelas duas protagonistas, Margarida e Beatriz, que, de suas antecessoras ilustres - a Beatriz de Dante e as Margaridas de Goethe e Dumas - conservam apenas o nome, impossibilitadas por suas personalidades e condutas de exercer o papel de guia espiritual e modelo de virtude na desgraça das homônimas.

Contrariamente ao que se passa no cenário de Os mistérios de Paris, a pacificação do leitor, pautada na correta distribuição de castigos e perdões entre maus e bons não é o que interessa, já que o que lhe é mostrado é um mundo cujo motor é a vontade individual devidamente reduzida a uma sucessão de caprichos de vária ordem, a ponto de Rafael Garção, um dos protagonistas, depois de mover mundos e fundos para conquistar a prima Beatriz, casada com Nicolau, rapidamente vê esfriar seu amor por ela (sobre o qual não são dadas garantias inequívocas ao leitor), o que é intensificado pela inveja que sente da felicidade de Ricardo, também este um amante dedicadíssimo que entretanto sobrevive à fatal crise que advém de sua separação de Margarida, a francesa fatal, para casar-se com Laura, uma rica brasileira. 
Para um leitor afeito à boa ordem de Os mistérios de Paris, esse parecerá um estranho mundo, em que bem e mal estão mais misturados do que deviam e, o que é pior, não há um narrador que os separe devidamente. Sua intervenção, do começo ao fim da narrativa é, como acontece frequentemente em Camilo, francamente galhofeira, não dando margem a que o leitor se satisfaça com o arremedo de "moral da história" apresentado no desfecho. Morto Nicolau de Mesquita, integrante do quadrilátero amoroso que se articula e rearticula ao longo da história, conclui o narrador: "Vimos o que é a justiça de Deus na terra: noutros mundos é-nos defeso devassá-la" ${ }^{10}$.

Não se exprime com isto qualquer convicção a respeito do funcionamento da justiça divina em todos os planos e, sobretudo, ao indicar-se que pode haver uma diferença entre a justiça divina aplicada no plano terreno e aquela distribuída em outros mundos, o que faz o narrador é sugerir que, ao fim e ao cabo, a tal justiça divina é mera projeção da expectativa humana baseada em convenções do que seja o certo e o errado, distintamente definidos, quando o que predomina neste mundo é resultado do amálgama entre os dois. A reforçar esta perspectiva, as palavras finais do romance, pronunciadas melancolicamente por Martinho, filho de Beatriz, ao contemplar o retrato da mãe, morta: "Como não haveria de perdê-la o mundo, se ela era tão formosa!" ${ }^{11}$ o fecho justifica a trajetória da mãe, definitivamente restringindo o campo de interesse ao plano das ações humanas, já que, mais uma vez, é ele que importa. Beatriz perde-se, naturalmente, e isso é tudo, não entra nessa conta o castigo divino, nem mesmo aquele aventado pelo narrador poucos parágrafos antes.

Colocados lado a lado os três romances, observa-se que, tanto no que diz respeito às questões relacionadas à constituição do indivíduo quanto àquelas ligadas ao estabelecimento e manutenção do modelo literário, há um processo de acirramento da distância que separa Camilo do ambiente da fruição descompromissada. Em $O$ demónio do ouro, considerando-se o título, o que se oferece como expectativa possível ao leitor é uma parábola sobre o poder nefasto do dinheiro e, consequentemente, a tragédia em que redundam as ações ditadas pela cobiça. Se isso fosse tudo, estaríamos diante de uma narrativa que seguiria o padrão definido pelo modelo folhetinesco à la Sue. Mas há mais.

Sem dúvida, há um mal que preside as ações humanas, aqui e ali associado, mais indireta que diretamente, ao que é da ordem do demoníaco, o que, pela primeira vez nestas três narrativas, é indicativo da presença algo inequívoca do sobrenatural. Entretanto, dada a absoluta fluidez desse demo- 
níaco, torna-se difícil relacioná-lo a um possível esforço por parte do autor para recuperar aquela clara distinção entre bem e mal, cristãmente definida, cara ao modelo. O modo como o sobrenatural é construído na narrativa remete-nos àquela caracterização de Francesco Orlando do que ele chama de "sobrenatural de transposição", um estatuto literário que assume a função de repor, em um mundo dessacralizado, a discussão sobre o mal que parece transcender a escala do que se convencionou como humanamente possível.

Com a guinada histórica que acelerou como nunca os ritmos do progresso, o presente começava a mostrar aspectos percebidos como enigmáticos, e não só traumáticos. Transpô-los para o sobrenatural, com o fito de lhes conferir significado, consistia em recorrer a algo que é misterioso por excelência, e o é a priori, sendo também algo, por excelência anterior. Assim, o sobrenatural reencontra uma consistência ontológica ${ }^{12}$.

Em um contexto que abriga tal estatuto, o mal, sobrenaturalmente concebido, mostra-se, autonomeia-se, não dando margem a que haja dúvidas quanto à dimensão a que pertence. Sua monstruosidade demoníaca, o horror que provoca a mera sensação de sua presença, eleva-se a proporções gigantescas porque a ele não há um bem que se contraponha. Ele abarca tudo, corrói tudo, sem para isso precisar de justificativas palpáveis. Em Demónio do ouro esse mal distribui-se equilibradamente entre os dois volumes nas figuras de Fowler e Serafim Gonçalves. O primeiro é o cúpido inescrupuloso, antagonista do herói, Manuel Vieira, e o segundo, o jovem para quem a prática da extrema violência não provoca qualquer aversão.

Nesta obra, como em nenhuma das anteriores, aquela gostosa vertigem provocada pela sucessão das peripécias prevista pelo modelo transforma-se em instrumento de tortura. A vertigem das ações passa a encobrir completamente a densidade de suas implicações, de seus desdobramentos e acaba por fazer perder de vista a relação causa-consequência, cara tanto ao modelo de entretenimento quanto ao sério, envolvendo as experiências humanas em uma atmosfera de melancolia desesperada que repete e repisa a inutilidade de toda vida humana, não apenas a dos condenados pela prática do mal. Tal é o caso daquele Serafim Gonçalves, o anjo vingador sempre movido pela fúria cega, violento, frio, ao mesmo tempo selvagem e fino raciocinador. É ele o líder de um vasto grupo - os mais de oitocentos herdeiros da fortuna de Manuel Vieira - tomado por forças obscuras, que não é difícil identificar como sobrenaturais, principalmente porque o narrador nunca as 
explica, optando por apresentar-nos essas trajetórias de autodestruição e destruição do ambiente circundante como resultado de infernos pessoais. $O$ padre Bento do $1^{\circ}$ volume e o próprio Serafim são exemplares desses endemoniados de si próprios, cheios de atitudes ambíguas e contraditórias.

Seguindo o mecanismo dos dois romances anteriores, o vínculo com o modelo estabelece-se pela via deste sobrenatural que ameaça ganhar palpabilidade na narrativa mas nunca o faz porque os argumentos do narrador no sentido de legitimá-lo são sempre inconsistentes. Há, por exemplo, a referência a uma maldição do ouro inglês que, distribuído pelo boníssimo Manuel, apenas provoca destruição porque, entre outras coisas, desvia os herdeiros do trabalho ou aguça sua cobiça e a dos que não são contemplados pela herança. Mas esta justificativa não se sustenta. E, afinal de contas, o ouro parece ser apenas a face externa de um mal para o qual não há remédio porque já ninguém se importa com ele: a solidão, o isolamento, do nascimento até a morte. Os que se redimem ao longo do romance, livrando-se dos infernos pessoais, são aqueles que, pelas vias e motivos mais diversos, tornam-se objeto da atenção pessoal de alguém - daí o ouro de Manuel não ter surtido o efeito desejado, resgatando seus irmãos e a horda de miseráveis das aldeias por onde ele passou no início da vida. Manuel foi, ele próprio, exemplo disso quando João Vieira tomou-o como filho. Mas para Serafim esse outro demora a chegar e acaba por não vir a tempo de salvá-lo. A relação que trava com o confessor quando espera o cumprimento de sua sentença de morte é um belo exemplo de como se pode chegar à redenção possível. Num mundo em que não há o consolo dos braços da divindade, é no interesse que venhamos a suscitar no outro, naquele semelhante, naquele irmão em desespero que pode estar a salvação, que não garante o paraíso porque, como já ensinou o narrador de $O$ esqueleto, esse é um assunto que não nos compete.

Novamente, como acontece em $O$ esqueleto, a recompensa ou punição divinas não são balizas efetivas. Aparecem como elementos do discurso, mas estão vazios de peso. Quando muito, seu sentido é o oposto do que preveem as convenções. Voltando à história da maldição do ouro, que teria sido responsável pelas desgraças na vida de todos os que com ele se envolveram, quando o romance está terminando diz-nos o narrador:

Não tenho notícia de existir alguém que proceda das famílias contempladas com os 1.200 contos de Manuel Vieira. Aquela santa gente de Courelas foi povoar o céu, depois que repartiu pelos pobres as últimas relíquias dos seus haveres ${ }^{13}$. 
Conclui-se com isso que, se a morte é o grande castigo, nada separa bons de maus.

Quanto ao antagonista do $1^{\circ}$ volume, sua atuação está a serviço de demonstrar que o mal não conhece fronteiras geográficas. Nas bases do modelo literário, o deslocamento da ação para regiões remotas tinha a função de garantir que as condutas equívocas que porventura tomassem assento na narrativa fossem próprias de homens pertencentes aos tempos escuros da Idade Média ou a sociedades fora dos limites da civilização - como aquela de Galícia abaixo que vimos referida a propósito de Gregório. Não é esse o caminho adotado por Camilo. Johnson Fowler, sendo inglês, é um legítimo integrante do mundo civilizado, o que está longe de ser suficiente para garantir sua honestidade, entre outras qualidades que comporiam o perfil de uma pessoa "correta", "civilizada". E, não contente em demonstrar sua incivilidade em sua terra, ele desloca-se para um ponto remoto do globo, a selva amazônica, para demonstrar como a canalhice floresce e sobrevive muito bem acima e abaixo do Equador. Sua figura e trajetória são elementos importantes em uma reflexão como a que se propôs aqui, interessada no ultrapassamento das leituras críticas que partam da ideia de que existe um contexto de produção que detém a marca de originalidade absoluta de um modelo literário e assuma que tudo o que se escreva fora dele resultará menor, menos abrangente em sua proposta. Ajuda-nos a relativizar essa convicção o caso de Drácula, um filho temporão da "novela do terror grosso" que, coisa espantosa, diferentemente deste exemplar extraído da literatura portuguesa, mais de 20 anos depois de lançado o segundo volume de $O$ demónio do ouro, volta ao mote do estrangeiro não-civilizado para reafirmar a confiança na Europa civilizada como detentora do poder de separar o bem do mal. Se é assim, foi Bram Stoker, e não Camilo Castelo Branco, que levou para casa o bastão do entretenimento na corrida da seriedade.

\section{REFERÊNCIAS}

BRANCO, Camilo Castelo. O demónio do ouro. Lisboa: Livraria Editora de Mattos Moreira, 1874 . Coisas espantosas. Lisboa: Parceria António Maria Pereira, 1902 . o esqueleto. 8. ed. Lisboa: Parceria António Maria Pereira, 1948. . Esboços e perfis literários. Boémia do espírito. Porto: Lello \& Irmão, 1959.

COELHO, Jacinto do Prado. Introdução ao estudo da novela camiliana. Lisboa: Imprensa Nacional-Casa da Moeda, 1982. 1. v.

ECO, Umberto. Eugène Sue, Je suis socialiste. In: SUE, Eugène. I misteri di Parigi. Milano: BUR-Rizzoli, 2011 
MORETTI, Franco. O século sério. In: (Org.). A cultura do romance. São Paulo: CosacNaify, 2009.

ORLANDO, Francesco. Estatutos do sobrenatural na narrativa. In: MORETTI, Franco (Org.). $A$ cultura do romance. São Paulo: CosacNaify, 2009.

Submetido em: 29/03/2013

Aceito em: 30/06/2013 